\title{
XXX. Water-pipes that do not burst with frost
}

\section{Vernon Boys}

To cite this article: C. Vernon Boys $(1882)$ XXX. Water-pipes that do not burst with frost , Philosophical Magazine Series 5, 13:81, 244-248, DOI: 10.1080/14786448208627178

To link to this article: http://dx.doi.org/10.1080/14786448208627178

曲 Published online: 28 Apr 2009.

Submit your article to this journal $2 \pi$

Џ Article views: 2

Q View related articles $₫$ 
tive index in the red. We may say that we have a hint of this; for if we represent the refractive indices by the ordinates of a curve in which the squares of the reciprocals of the wave-lengths are abscisse, this curve presents a point of inflection*. In the part corresponding to short waves it is concave upwards; in the part corresponding to long waves it is concave downwards: the curvature, however, is very slight. Does it not seem possible, looking at the matter from the purely optical point of viow, that if we could examine the spectrum below the absorption in the infra-red, we should find the effect of anomalous dispersion, and that the refractive index of such long waves might even be so high as $2 \cdot 6$ ? To test this experimentally in a conclusive manner would probably not be easy. Perhaps the best chance of finding how these long waves are refracted would be to experiment on the rays from a thermopile to a freezing-mixture. Without an actual measurement of a refractive index below all strong absorption, it cannot be said that experiment is in contradiction to the Electromagnetic Theory of Light; for a strong absorption introduces a discontinuity into the spectrum which forbids us from using results on one side of that discontinuity to infer what they would be on the other side.

XXX. Water-pipes that do not burst with Frost. By C. Vernon Boys, Demonstrator of Physics, Normal School of Science, South Kensington $†$.

DURING the severe weather of last winter, Mr. L. S. Powell proposed to me a scheme for preventing the possibility of water-pipes bursting through frost; and I have since learnt that Mr. Mangnall, of Manchester, independently hit upon the same idea. As far as I can remember, there were some letters in the 'Times' describing the use of indiarubber pipes containing air inserted in the service-pipes. This would obviously prevent pipes from bursting; for the pressure is of a nature that is relieved by a comparatively small expansion; and this the india-rubber tube allows to take place in the surrounding water when it collapses. There is, however, one serious objection to this, which is the possibility of the detachment of one end of the flexible tube, in which case a rush of water might cause it to accumulate in one place and obstruct the passage.

* Proceedings of Royal Society, 1877.

$\dagger$ Communicated by the Physical Society, having been read at the Meeting on November 12,1881 . 
Mr. Powell's plan is to make the piping elliptical-either before it is laid, in which case it may be made of that form originally or by passing round pipe through rollers, or afterwards, when suitable hand-squeezers will effect the result without the necessity of removal. As will afterwards be seen, it is not necessary that the pipe should be elliptical throughout; if left round under staples and in other inaccessible places, the adjacent elliptical portions ensure safety. The principle, of course, is obvious. As is well known, the Bourdon pressuregauge depends on the fact that the area of an elliptical pipe is less than that of a circle of equal perimeter: therefore during increased pressure its section becomes more circular; increased circularity of section produces diminished curvature in the form of the pipe; and so the movements of the end of the pipe are used to measure pressure. Thin brass is used for this purpose, and is so elastic that it returns to its original form when the pressure is removed; and so an indefinite number of increments and decrements of pressure may be measured by it. The case of the elliptical water-piping is different. Here there is not a definite pressure to withstand, but a definite increase of volume; and, moreover, if this increase of volume is resisted, a practically infinite force arises to break down the resistance. The question then is, how best to allow of this increase of volume. The method of the indiarubber pipes I have already mentioned. The other plan is to make them of an elliptical or other-thanround section. There is, however, far more in this suggestion than one would be likely to see at first. Consider the case of a round pipe in which water is beginning to freeze. Increase of volume must take place somewhere. No pipe can be absoIntely uniform in strength everywhere. So wherever a place occurs which happens to be a little weaker than the rest, no matter how little, that place will stretch, and necessarily stretch more than other places. But when a round pipe stretches, two things happen-its diameter incroases and its thickness decreases; therefore, as the strength of a tube to resist bursting is inversely as the diameter and directly as the thickness, each of these effects makes the stretched portion still weaker than the neighbouring parts; therefore a round pipe under the action of frost is in a state of unstable equilibrium; the consequence is, knobs form on the pipe, and ultimately burst.

Now consider the case of an elliptical pipe, of such strength, of course, as to stand the ordinary water-pressure. As before, suppose some portions are weaker than others. When expansion takes place they will suffer most, and will begin to give way. But an elliptical pipe on giving becomes more circular,

Phil. Mag. S. 5. Vol. 13. No. 81. April 1882. X 
and this the more easily as its section departs more from the circle; so the very fact of its becoming more circular makes it less ready to change its form. In a very little while, therefore, though originally weaker, it will become as strong as neighbouring portions: therefore an elliptical pipe under the action of frost is in a state of stable equilibrium, and, instead of giving way in the bulbous manner of a circular pipe, it uniformly becomes more circular. Now the expansion of water in becoming ice is known; and therefore it is easy to calculate by compound interest how many complete freezings (that is, freezings from one end of the pipe to the other) any given section of piping will stand before it becomes round. Of course, in practice, the whole length of a pipe does not get frozen; yet if it were originally all of it elliptical, the unfrozen portions would be effective in preventing the more exposed parts from bursting; because as soon as the exposed portions have become rounder than the rest, the latter, and not the former, will yield. If two places in the pipe become completely frozen through and then the intermediate portion freezes, it is true that parts beyond the frozen plug will have no effect.

Mr. Powell and I tried a series of experiments on the subject to see if, in practice, the pipes behaved as we expected. We obtained a quantity of $\frac{3}{4}$-inch lead pipe, about $\frac{1}{10}$ inch thick, and some thin composition pipe of the same size. The piping was cut into Jengths of about three feet; half of them were squeezed into an approximately elliptical form, and the rest left circular in section. The degree of ellipticity was such that the major axis was a little more than twice the minor axis. One end of each pipe was squeezed together and soldered. Into the other ends brass plugs cut with a sharp thread were screwed while hot, having been previously smeared with a cement of rosin, beeswax, and red-ochre. After these plugs were inserted and while still hot, the lead was, as an additional precaution, squeezed over a narrower portion of the plug above the screw-thread. In each plug a hole had been drilled and tapped. Through these holes the pipes were filled with water; and then iron screws, with washers of leather boiled in beeswax and tallow, were used to make a tight joint. The pipes were then all laid together in a long box, and surrounded with a freezing-mixture. When a short test-pipe of the same diameter showed that the water was completely frozen, the pipes were removed and thawed. The round composition pipe was burst. The round lead pipe was swollen in an irregular manner. The elliptical piping had become slightly rounder, but was perfectly uniform in shape from end to end, which 
was not the case when it was put in the freezing-mixture. The most noticeable thing, however, was the fact that all the unburst pipes had become good water-hammers, and this showed that leakage could not have occurred. The screws were removed, the pipes filled, again screwed up and refrozen, and this was repeated till all were burst. The round lead and the thin elliptical composition pipe burst at the third freezing, and the elliptical lead pipe at the sixth. Judging from tho fact that it required three freezings to burst the round pipe, one might be led to suppose that a round pipe would last equally long under ordinary conditions, which is certainly not the case. The reason is that, under ordinary conditions, a greater length freezes at a time and more slowly; and a slight inequality arising, the expansion from a greater volume of water is concentrated on the weaker places, which therefore give way during the second, if not the first, freezing of the water.

It might be thought that, as the onter layers of ice are below the freezing-point when the pipe is being cooled, they would not act as a plastic body and accommodate themselves to the changing form of the pipe; but no doubt can remain as to their behaviour in this respect when the pipe is cooled in air; for in the freezing-mixture, where the rate of cooling must be much more rapid, such accommodation takes place perfectly, even thin composition pipes changing their form and becoming round. The apparent plasticity of the ice may depend on fracture and regelation; for if the outer layers are bolow the freezing-point, and a bursting-pressure is brought to bear on the compound pipe formed of lead and ice, it might yield, the lead bending and the ice cracking, and so allowing the water to penetrate the cracks and freeze in them. Whether this action takes place or not does not much matter: the result, as in the somewhat different case of glacier-motion, is much the same.

If the pipe is made of such a form that it will not become round till it has been completely frozen, say, three times, it will take a great many frosts to burst it, as those parts that do not freeze easily will protect the more exposed portions; so absolute security may be relied upon till ordinary round pipes have burst once or twice; and then the now nearly round ones may be squeezed back to their original form. The choice, then, is between two evils; either burst pipes, with the usual damage and cost of repair, or the trouble of inspection every second or third time that the neighbours find that the "thaw" has burst theirs.

We thought it possible that iron might be sufficiently elastic $\mathrm{X} 2$ 
to return to its original form; and so we froze water in two $\frac{3}{4}$-inch iron gas-pipes, one round and one which had been flattened when red-hot. The round pipe burst the first time; the flat one did return slightly when thawed, but not enough to prevent its bursting during the second operation.

No doubt most people will not consider this proposal of Mr. Powell's a satisfactory cure for burst pipes ; they would like something which could be fixed in their houses and which would be always safe without further attention. But till such a discovery is made, I think elliptical pipes give the best solution of a problem which has troubled every householder.

As the subject of this paper is of physical as well as general interest, I hope that it may be considered not unworthy of the attention of the Physical Society.

XXXI. Electro-optic Experiments on various Liquids. By JoHN Kerr, LL.D., Free Church Training College, Glasgow.

[Concluded from p. 169.]

Sulphides, $\left(\mathrm{C}_{n} \mathrm{H}_{2 n+1}\right)_{2} \mathrm{~S}$.

13. THESE are purely negative, and rise in power as $n$ 1 increases; they are weaker than the corresponding oxides, but much stronger than the hydroxides.

Ethyl sulphide, not a clean liquid, required the jar and 10 to 20 turns of the plate. The effect was purely negative, strengthened by compression parallel to lines of force, and extinguished by tension.

Butyl sulphide, tried as a nonconductor, gave a very faint effect, which was barely characterizable as negative. Tried then as a conductor, with increasing charges of the jar, it gave a set of brilliant effects, always purely negative.

Amyl sulphide, a feeble photogyre, hardly separating the red and blue at extinction, was rather stronger than the last. It acted well as a nonconductor, giving a clear effect which was purely negative. As a conductor, with increasing charges, it gave increasingly brilliant effects, always negative by both tests.

Ethyl disulphide was also examined, and was found to be purely negative, like the protosulphide, but much stronger. As a nonconductor it gave a pure and moderately strong effect; and as a conductor, with increasing charges of the jar, it gave a fine series of restorations, all purely negative, extinguished perfectly by tension parallel to lines of force. 